\title{
Erratum to: Malaria and Economic Evaluation Methods: Challenges and Opportunities
}

Tom L. Drake ${ }^{1,2}$ - Yoel Lubell ${ }^{2,3}$

Published online: 10 February 2017

(C) Springer International Publishing Switzerland 2017

\section{Erratum to: Appl Health Econ Health Policy DOI 10.1007/s40258-016-0304-8}

An Online First version of this article was made available at http://link.springer.com/journal/40258/onlineFirst/page/ 1 on 19 Jan 2017. However, there was an error in Fig. 2. Although the figure was correct in the original manuscript, an error was introduced while replacing it with a higher resolution file during the production of the article. The article has now been updated with a corrected version of Fig. 2, which is also provided in this erratum.

The online version of the original article can be found under doi:10.1007/s40258-016-0304-8.

Tom L. Drake

tom.d@tropmedres.ac

Myanmar Oxford Clinical Research Unit, Yangon, Myanmar

2 Nuffield Department of Medicine, University of Oxford, Oxford, UK

3 Mahidol-Oxford Tropical Medicine Research Unit, Mahidol University, Bangkok, Thailand

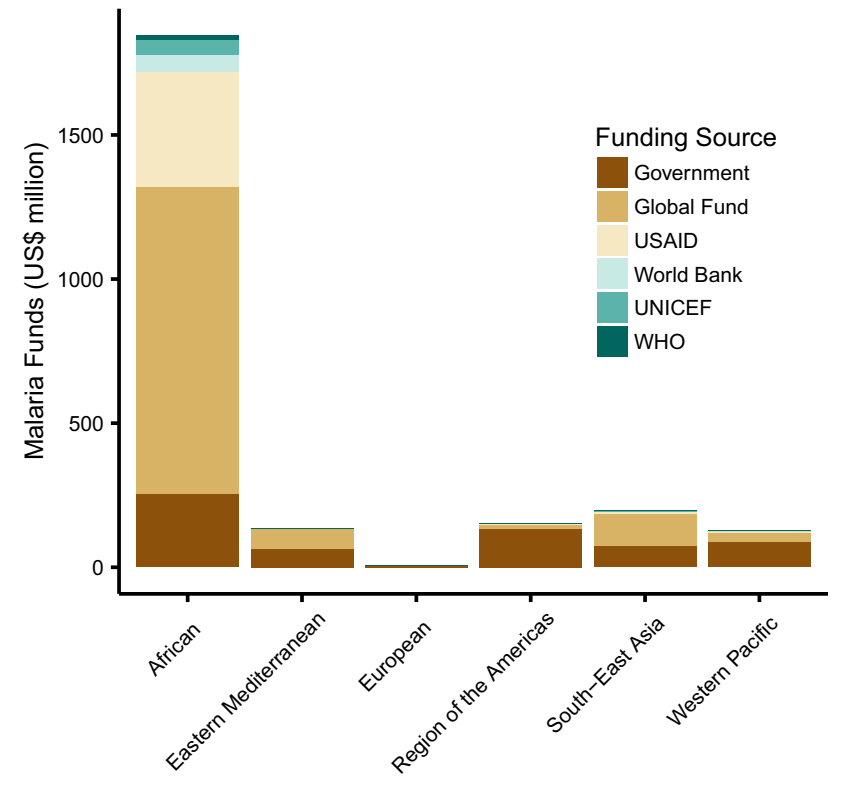

Fig. 2 Sources of funding for malaria control and elimination in 2014 